\title{
Bystanders: Plasco Building Collapse in Iran, 2017
}

\author{
Mohammad Heidari, PhD; Rahim Ali Sheikhi, PhD; and Hamid Jafari, PhD
}

$\mathrm{A}$ fter an incident, bystanders are usually the first people to arrive at the scene, ${ }^{1,2}$ and for various reasons they gather around it. The presence and interventions of the people at the scene of the event have different effects on relief and assistance to the victims. Sometimes they act as facilitators (calling relief agencies, helping the victims, and helping relief forces) and sometimes they act as a barrier (unnecessary gathering at the scene of an incident can prevent immediate relief and lead to a new crash). ${ }^{1,3-5}$

The iconic 17-story Plasco building, the first symbol of modernity in Tehran, caught fire on January 19, 2017 at approximately 7:58 AM local time (4:30 GMT). Despite all the efforts made by firefighters for over 3 hours, finally at around 11:20 AM the building suffered a total vertical collapse (Figure 1).

From the first minute of collapse, despite traffic bans by the police, some citizens insisted on gathering at the site. The police repeatedly urged people to refrain from gathering at the Plasco building. According to rescuers, the crowds surrounding the Plasco building disrupted rescue operations and put the bystanders themselves in danger. The unreasonable presence of people who had gathered to watch the accident at the Plasco building slowed down the evacuation process and put the lives of firefighters in danger.

On the day of the incident, other than police officers, relief workers, and journalists, most of the people at the scene had come to satisfy their curiosity and take photos and videos. In the early hours of the event, a short video was broadcast on social networks that showed the ambulance caught in the crowd, its driver asking people to open the road (Figures 2 and 3 ). This incident was a clear example of unnecessary gathering and preventing the timely action (critical time) of relief teams.

In general, bystanders are people who attend a scene after an accident. Usually these people have no knowledge about disaster relief and aid to victims and have not been trained. The accumulation of bystanders can prevent rapid relief and desirable aid to victims. Sometimes attendance at the accident scene not only does not help, but also may cause a cascade of events that brings harm to the bystanders and others. ${ }^{6,7}$

\section{FIGURE}

\section{View of Plasco Building Collapse Scene.}




FIGURE 2

View of Bystanders in Plasco Building Collapse Scene (photo 1).

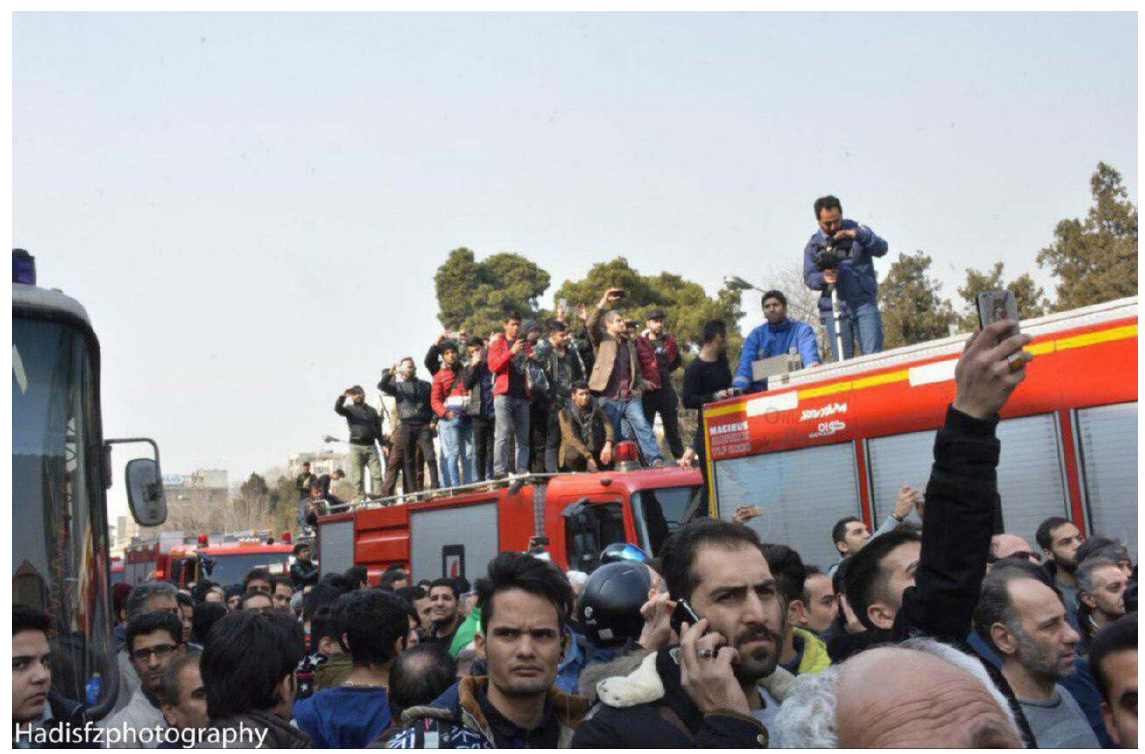

FIGURE 3

View of Bystanders in Plasco Building Collapse Scene (photo 2).



Cultural beliefs and values play an important role in the presence and intervention of people at the scene of events. In a study conducted by Khorasani et al, in the cultural context of Iran, factors such as willingness to help, humanitarian assistance, individual curiosity, excitement, and disorganized cooperation lead to a crowded crash scene and poor coordination. ${ }^{1}$

An approach proposed by the World Health Organization to reduce deaths and injuries caused by accidents is to train 
bystanders and upgrade them to first responders. This can be a strategic and important factor in reducing mortality and complications from accidents. ${ }^{8-11}$

In developed countries, educating people at the community level about how to deal correctly with scenes of incidents and injuries is implemented as a comprehensive program. For example, according to programs developed in the United States, every year $6 \%$ of the total population of the country should be trained. ${ }^{12}$

It is a fact that in most cases bystanders arrive at the scene of an incident before relief agencies do, and time is a very important factor in helping victims and reducing deaths and injuries. Therefore, attention to community education and upgrading bystanders to first responders as much as possible, especially in middle- and lower-middle-income countries, can have a significant role in reducing the complication of accidents.

This incident showed that community risk perception in various events is low. As stated in the Sendi framework (2015-2030), ${ }^{13}$ actions must be taken to promote national strategies to strengthen public education and awareness of disaster and event risk reduction. These strategies can disseminate disaster risk information and knowledge through campaigns, social media, and community mobilization and can enhance collaboration among people at the local level to disseminate disaster and event risk information through the involvement of community-based organizations and nongovernmental organizations. Also, special mass media can increase risk perception in the community with actions such as educating and informing people about how to deal with events, what should and should not be done on the scene of an incident, how to help injured people, and how to interact with relief forces.

\section{About the Authors}

Department of Medical and Surgical, School of Nursing and Midwifery, Shahrekord University of Medical Sciences, Shahrekord, Iran (Dr Heidari); Department of Health in Emergency and Disaster, School of Health Management and Information Sciences, Iran University of Medical Sciences, Tehran, Iran (Dr
Heidari and $\mathrm{Mr}$ Jafari); Health Management and Economics Research Center, Iran University of Medical Sciences, Tehran, Iran (Dr Sheikhi).

Correspondence and reprint requests to Rahim Ali Sheikhi, School of Health Management and Information Sciences, Iran University of Medical Sciences, No 6, Rashid Yasemi Street, Vali-e-asr Avenue, Tehran, Iran. P.code: 1995614111 (e-mail: rahim.shaykhi94@gmail.com).

\section{REFERENCES}

1. Khorasani-Zavareh D, Khankeh HR, Mohammadi R, et al. Post-crash management of road traffic injury victims in Iran: stakeholders' views on current barriers and potential facilitators. BMC Emerg Med. 2009;9(1):8.

2. Pelinka LE, Thierbach AR, Reuter S, et al. Bystander trauma care-effect of the level of training. Resuscitation. 2004;61(3):289-296.

3. Haghparast-Bidgoli $\mathrm{H}$, Hasselberg $\mathrm{M}$, Khankeh $\mathrm{H}$, et al. Barriers and facilitators to provide effective pre-hospital trauma care for road traffic injury victims in Iran: a grounded theory approach. BMC Emerg Med. 2010;10(1):20.

4. Alinia S, Khankeh H, Maddah SS, et al. Barriers of pre-hospital services in road traffic injuries in Tehran: the viewpoint of service providers. Int $J$ Community Based Nurs Midwifery. 2015;3(4):272-282.

5. Tannvik T, Bakke H, Wisborg T. A systematic literature review on first aid provided by laypeople to trauma victims. Acta Anaesthesiologica Scandinavica. 2012;56(10):1222-1227.

6. Koenig KL. Koenig and Schultz's Disaster Medicine: Comprehensive Principles and Practices. New York: Cambridge University Press; 2010.

7. Malta Hansen C, Kragholm K, Pearson DA, et al. Association of bystander and first-responder intervention with survival after out-ofhospital cardiac arrest in North Carolina, 2010-2013. JAMA. 2015;314(3):255-264.

8. Arbon P, Hayes J, Woodman R. First aid and harm minimization for victims of road trauma: a population study. Prehos Disaster Med. 2011;26(4):276-282.

9. Tiska M, Adu-Ampofo M, Boakye G, et al. A model of prehospital trauma training for lay persons devised in Africa. Emerg Med J. 2004;21(2):237-239.

10. Mock C, Quansah R, Krishnan R, et al. Strengthening the prevention and care of injuries worldwide. Lancet. 2004;363(9427):2172-2179.

11. Callese TE, Richards CT, Shaw P, et al. Layperson trauma training in low- and middle-income countries: a review. J Surg Res. 2014;190(1):104-110.

12. Anderson ML, Cox M, Al-Khatib SM, et al. Rates of cardiopulmonary resuscitation training in the United States. JAMA Intern Med. 2014;174(2):194-201

13. United Nations Internationa Strategy for Disaster Reduction. Sendai Framework for Disaster Risk Reduction 2015-2030. https://www.unisdr.org/ we/coordinate/sendai-framework. Published 2015. Accessed July 2, 2018. 